\title{
Inventory lot sizing and supplier selection for multiple products, multiple suppliers, multiple periods with storage space using lingo program
}

\author{
Muoyleang Sambatt ${ }^{1}$, Chirawat Woarawichai ${ }^{2}$, Thanakorn Naenna ${ }^{3}$ \\ ${ }^{183}$ Department of Industrial Engineering, Mahidol University, Nakhonpathom 73170, Thailand \\ ${ }^{2}$ Department of Industrial Engineering, Rajamangala University of Technology Lanna Tak, 63000, Thailand
}

\begin{abstract}
This study focuses on inventory lot sizing for supplier selection of multiple products; suppliers and periods with storage space constraint. The objective is to develop mathematical model. Lingo software program is used as solution tool. The proposed problem is found as mix integer linear programming (MILP) which beneficial for decision making of choosing optimal supplier and product in right period of time with minimum overall inventory cost.
\end{abstract}

\section{Introduction}

Lot sizing and supplier selection has become interesting topic in term of business practice as well as in academic study. Defining lot size and supplier selection strategy consist grave impact in purchasing as well as production and inventory cost. Lot sizing and supplier selection are two impressive decision makings procedure to minimize cost while maximize quality and service level. To this problem, the buyer could not decide separately so that it is required to combine them together by concerning on one main goal is to minimize cost as well as maximize quality and service level.

Meanwhile, there are more studying investigating on not only classical model, until now there is extension and broad research done focusing on several various aspects of lot sizing considering on supplier selection. There is study on periodic review concerning to find number of ordering quantity with fixed review time while some study on continuous review lot sizing with fixed quantity of ordering. Some studying on single period single product inventory lot sizing with capacitated resource, some are curious about multiple periods, multiple products lot sizing with deterministic or stochastic demand and so on with different aspect.

All of above description is the crucial factor lead this study to focus on inventory lot sizing for selecting supplier with multiple products, multiple suppliers, multiple periods considering on storage space in periodic review. This study expects to develop mathematical formulation of proposed problem and obtain a model for a decision making to choose optimal supplier providing right product at right time.

\section{Literature Review}

Good inventory management can be done based on good production planning as well as replenishment controlling. Math model is required to develop following proposed problem including linear programming, non-linear programming, mixed integer programming, geometric programming, gradient-based nonlinear programming and dynamic programming. It was illustrated that when problem become NP-hard, it is required to use heuristic tool to solve those problems [2].

\subsection{Lot sizing}

Lot sizing is the most crucial issue and one of most complicated problem in production planning. Lot sizing defines time and amount of product to produce to minimize overall cost. Lot size objective is to define quantity to order to reduce replenishment time. Lot-sizing is an impressive factor of production or order and inventory planning $[1,3,5]$. Lot sizing planning and scheduling of production is really required for many kinds of production environment. There are much attention focusing on integration of lot sizing in practice in real activity [14]. Lot sizing is the crucial determinant in supply chain management to select optimal supplier to obtain the best product, lot size, and right time to order during a finite planning horizon [13].

\subsection{Inventory model classification}

There are several criteria to define classification of inventory model such as finite or infinite characteristic of 
planning horizon, single or multiple number of items, fixed or variable order quantity which found as periodic or continuous review, zero or non-zero lead time, capacitated or non-capacitated capacity, deterministic, static or dynamic and stochastic demand, single or multiple echelon stocking and finally consider to allow or not allow unsatisfied demand condition as illustrating in figure 1 [11]. There is literature review of inventory lot sizing problem. It was indicated that inventory planning has been a complicated problem. The study has been review focusing on four classifications such as singlelevel unconstrained resources, single-level constrained resources, multiple-level constrained resources, and multiple-level unconstrained resources. This review illustrated both real practice as well as academic study. It was found that capacity factor and fact of plant environment such as scrap, demand uncertainty or unspecific data are the root for research in lot sizing field [9].

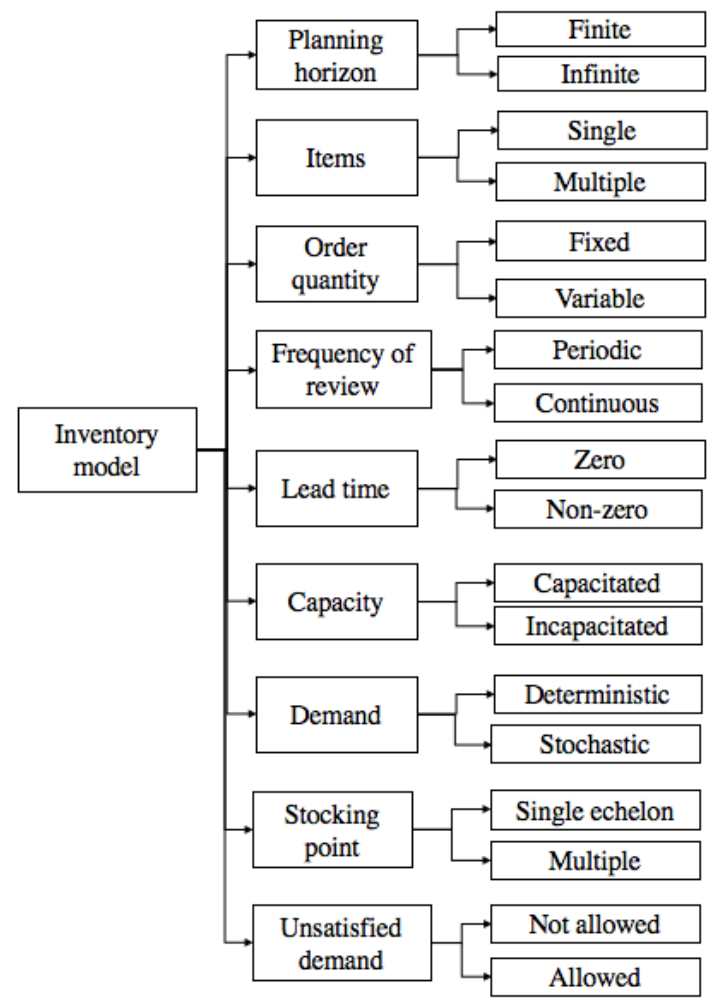

Fig. 1. Inventory model classification.

\subsection{Inventory lot sizing and supplier selection}

Supplier selection is an important indicator and significant complexity in organization [8]. Supplier selection is found as a crucial concerning in lot sizing [16]. Meanwhile, lot sizing and supplier selection are two impressive decision- making procedures which aims to define size, is really main thing to concern to minimize total cost [11]. A problem with storage space constrained buyer procures a single product in multiple periods from multiple suppliers was studied [6]. Lot sizing is a kind of tactical decision, the crucial determinant in supply chain management. It is really important to select good supplier to obtain the best product, lot size, and right time to order during a finite planning horizon $[5,12,14]$. There are many study focus on supplier selection and procurement lot sizing. The study is to select the best suppliers and determine optimum quantity from selected supplier focusing both tangible and intangible procedure as well as time. Supplier selection is found as multiple criteria decision making [17]. There are plenty of study pay more attention on lot sizing along with supplier selection. The crucial objective is to select which supplier and how much to make ordering from that choice of supplier. Defining lot size as well as supplier selection strategy consists grave impact in term of purchasing as well as production and inventory cost. Problem of lot sizing and scheduling is investigated [13]. Furthermore, there is study on multiple period lot sizing with supplier selection problem. The purpose is to decide what products to order in what quantities with which suppliers in which periods. An enumerative search algorithm and a heuristic was used to solve the problem; however, it is not process fast enough for real case of complicated problem [4]. There is study on lot sizing and supplier selection of multiple products and multiple suppliers which consist two multiple objective models concerning on shortage [12]. The study of multiple suppliers, multiple periods with quantity discount was investigated. The proposed problem focuses on finite planning horizon, fixed ordering quantity, independent and known demand with lead time. The proposed problem is formulated as mix integer programming and genetic algorithm was used as solution tool [2]. Lot sizing with supplier selection problem with multi-echelon, multi products defective supply chain network with stochastic demand was studied [7].

Right supplier selection could provide more benefit by eliminate purchasing cost as well as high competency in term of good corporation as known that supplier selection is the most pivotal indicator in purchasing management. The research was done focusing on decision making on appropriate selection of suppliers, and on assigning order quantities to these suppliers, in case of multiple sourcing, with multiple criteria and with suppliers' capacity constraints. The objective of this research is to minimize summation of purchasing cost, ordering costs and storage costs considering on some specific constraints such as limitations on buyer's budget, quality and service. The proposed model is formulated as a mixed integer non-linear programming model in order to solve multiple sourcing problem relating to total cost of logistic, net price, storage, transportation and ordering cost. GINO algorithm was used to solve proposed problem [19].

There is study on problem of multiple products, multiple period with deterministic zero lead time with known planning horizon demand and focus on storage space and budget constraints. This aims to optimize lot sizing for each supplier as well as reduce total inventory cost considering on join purchasing cost, transaction cost for suppliers and holding cost for left inventory. The proposed problem is developed as mix integer linear programming and LINGO 12.0 software program was used as solution tool [5]. 


\subsection{Lingo program}

Lingo program is a recommended optimization tool which illustrating mathematical model and see process of model by lingo solver. The model indicates computational time and solution method. There are four various kinds of solver such as direct, a linear, a nonlinear and a branch and bound solver. Direct solver help lingo defines all fixed variables and constraint from model and seeking whether model is linear or nonlinear. If there is nonlinear constraint or variables, so model is found as nonlinear programming. Lingo roles to build and solve mathematical model easier and effectively. It is capable to solve several kinds of model while it is required computational time and input data [15].

\section{Methodology}

\subsection{Math model development}

This study investigates on inventory lot sizing with supplier selection of multiple products, multiple suppliers, multiple period with storage floor space constraint in term of periodic review as seen in figure 2. Based on this, it is required to considered on ordering quantity $X_{i j t}$ which is vary depending on different period while reviewing time is fixed. This is done to define quantity of which product to order from which supplier in which right time period.

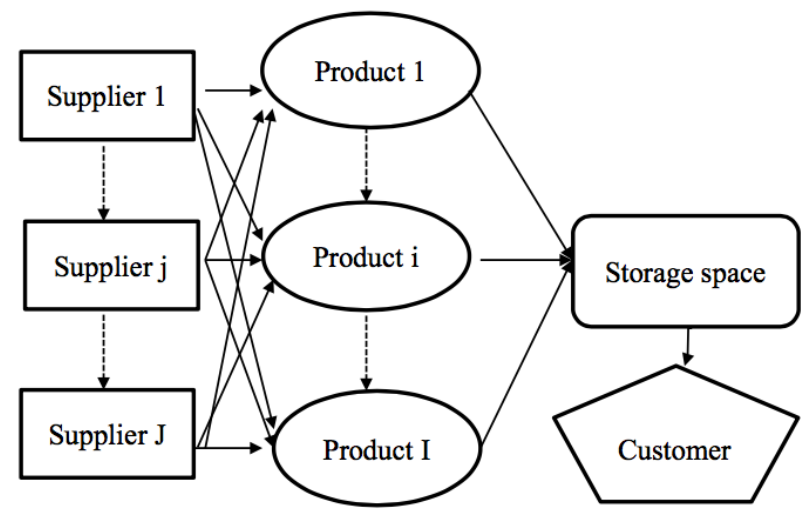

Fig. 2. Diagram of proposed problem.

\section{Assumption}

Random demand

Shortage is not allowed

Limited storage floor space

Inventory of item $i$ at beginning of planning period is 0

\section{Indices}

$\mathrm{i}=123 \ldots \mathrm{I}$ index of products

$\mathrm{j}=123 \ldots \mathrm{J}$ index of suppliers

$\mathrm{t}=123 \ldots \mathrm{T}$ index of periods

\section{Parameters}

$\mathrm{D}_{\mathrm{it}}$ : demand of product $\mathrm{i}$ in period $\mathrm{t}$

$P_{\mathrm{ij}}$ : purchase price of product $i$ from supplier $j$

$\mathrm{H}_{\mathrm{i}}$ : holding price of product $\mathrm{i}$

$\mathrm{O}_{\mathrm{j}}$ : transaction price from supplier $\mathrm{j}$

W: total available storage space

$\mathrm{f}_{\mathrm{i}}$ : storage space for the ith product

$\mathrm{I}_{\mathrm{it}}$ : Total inventory of each period

\section{Decision variable}

$X_{i j t}$ : ordering quantity of item $\mathrm{i}$ from supplier $\mathrm{j}$ with in time t.

$Y_{j t}$ : equal to 1 if make ordering for supplier $\mathrm{j}$ at time $\mathrm{t}$, equal to 0 otherwise

\section{Objective function}

The objective is to minimize total inventory cost as following description:

Minimum total cost $=$ Transaction cost + Purchasing cost + Holding cost

$$
\begin{aligned}
\operatorname{Min}= & \sum_{\mathrm{j}}^{\mathrm{J}} \sum_{\mathrm{t}}^{\mathrm{T}} \mathrm{o}_{\mathrm{j}} Y_{j t}+\sum_{\mathrm{t}}^{\mathrm{T}} \sum_{\mathrm{j}}^{\mathrm{J}} \sum_{\mathrm{i}}^{\mathrm{I}} \mathrm{P}_{\mathrm{ij}} X_{i j t}+ \\
& \sum_{\mathrm{t}}^{\mathrm{T}} \sum_{\mathrm{i}}^{\mathrm{I}} \mathrm{H}_{\mathrm{i}} \mathrm{I}_{\mathrm{it}} ; \quad \forall \mathrm{i}, \mathrm{j}, \mathrm{t}
\end{aligned}
$$

Subject to:

$$
\begin{gathered}
\mathrm{I}_{\mathrm{it}}=\mathrm{I}_{\mathrm{it}-1}+\sum_{\mathrm{t}}^{\mathrm{T}} \sum_{\mathrm{j}}^{\mathrm{J}} \sum_{\mathrm{i}}^{\mathrm{I}} X_{i j t^{-}} \sum_{\mathrm{t}}^{\mathrm{T}} \sum_{\mathrm{i}}^{\mathrm{I}} \mathrm{D}_{\mathrm{it}} ; \forall \mathrm{i}, \mathrm{j}, \mathrm{t} \\
\sum_{\mathrm{t}}^{\mathrm{T}} \sum_{\mathrm{i}}^{\mathrm{I}} \mathrm{D}_{\mathrm{it}} \sum_{\mathrm{t}}^{\mathrm{T}} \sum_{\mathrm{j}}^{\mathrm{J}} Y_{j t^{-}} \sum_{\mathrm{t}}^{\mathrm{T}} \sum_{\mathrm{j}}^{\mathrm{J}} \sum_{\mathrm{i}}^{\mathrm{I}} X_{i j t} \geq 0 ; \forall \mathrm{i}, \mathrm{j}, \mathrm{t} \\
\sum_{\mathrm{t}}^{\mathrm{T}} \sum_{\mathrm{i}}^{\mathrm{I}} \mathrm{f}_{\mathrm{i}} \mathrm{I}_{\mathrm{it}} \leq \mathrm{W} ; \forall \mathrm{i}, \mathrm{j}, \mathrm{t} \\
Y_{j t}=0 \text { or } 1 ; \forall \mathrm{j}, \mathrm{t}
\end{gathered}
$$

Equation (1) indicating objective function which composed of transaction cost, purchasing cost and holding cost. Transaction cost is summation of transaction price $\mathrm{O}_{\mathrm{j}}$ multiply with binary number $Y_{j t}$, purchasing cost is summation of purchasing price $P_{i j}$ multiply with ordering quantity $X_{i j t}$ [4]. Holding cost is summation of holding price $\mathrm{H}_{\mathrm{i}}$ multiply with total inventory $\mathrm{I}_{\mathrm{it}} \quad[4,10,18]$; (2) Inventory constraint is summation of inventory of each previous period with ordering number minus demand. (3) Shortage is not allowed [12], (4) Storage floor space required to be lower than total space W [5]. (5) binary number $Y_{j t}$ which equal to 1 if make purchasing from supplier $\mathrm{j}$ at period $\mathrm{t}$ and 0 , otherwise [12]. 


\subsection{Computational experiment}

In this section, a commercially optimization package LINGO 12.0 is used for solving proposed problem. Experiments are conducted on a personal computer with described feature as table 1 .

Moreover, data is generating in order to see the performance of proposed problem. The transaction price is generated in interval $[1 ; 3]$ mean random uniform distribution between 1 to 3 . Holding price is from interval $[1 ; 5]$, purchasing price is from interval $[5 ; 15]$; storage space for each product is from interval [0.1;0.3], total available storage space is 1800 square feet, demands are from interval $[30 ; 6500]$, inventory for item $i$ at the beginning of a planning period is assumed to be 0 . The interval of randomization of each parameter is shown in Table 2.

Table 1: Hardware and software

\begin{tabular}{|c|c|}
\hline Feature & Units \\
\hline MacBook Air & 13 Inch, 2017 \\
\hline Processor & $1.8 \mathrm{GHz}$ Intel Core i5 \\
\hline Memory & 8GB 1600Mhz DDR3 \\
\hline Graphic Intel HD Graphics & $60001536 \mathrm{MB}$ \\
\hline Lingo Software Program & 12.0 \\
\hline
\end{tabular}

Table 2: Interval value of data

\begin{tabular}{|c|c|}
\hline Parameter & Interval of random value \\
\hline $\mathrm{D}_{\mathrm{it}}$ & {$[30,6500]$} \\
\hline $\mathrm{H}_{\mathrm{i}}$ & {$[1,5]$} \\
\hline $\mathrm{O}_{\mathrm{j}}$ & {$[1,3]$} \\
\hline $\mathrm{P}_{\mathrm{ij}}$ & {$[5,15]$} \\
\hline $\mathrm{f}_{\mathrm{i}}$ & {$[0.1,0.3]$} \\
\hline $\mathrm{I}_{\mathrm{i} 0}$ & 0 \\
\hline $\mathrm{W}$ & 1800 \\
\hline
\end{tabular}

\section{Result and discussion}

The values of each parameter are generated randomly. Numerical examples with problem size of 3 products, 4 suppliers, 6 periods are presented to examine the performance of Lingo 12.0 as indicating in figure 3. This example, lingo output provides for selection product, supplier in each period such as following:

Product 1:

$X_{131}=542, X_{132}=5077, X_{133}=5077, X_{134}=2889, X_{135}=6257$, $X_{136}=2156$

Product 2:

$X_{231}=4948, X_{232}=1147, X_{233}=31, X_{234}=3808, X_{235}=4836$, $X_{236}=5994$

Product 3:

$X_{311}=1241, X_{312}=361, X_{313}=4364, X_{314}=2365, X_{315}=2130$, $X_{316}=4706$

Furthermore, problem is extended to be more complicated. The interval of randomization of each parameter is shown in Table 3. This problem is extended by consider on multiple products i from 3 items until 20 items, multiple supplier $\mathrm{j}$ from 4 to 22 with three different periods such as 6 periods, 12 periods and 24 periods.
As the proposed problem is extended to be greater and more complicated, lingo program could solve, and found that its mathematical model as mix integer linear programming (MILP) and provide global optimal solution which is right criteria to select optimal supplier, product with right period of time to reduce total inventory cost. Based on this result, lingo program software is effective to use as tool for optimize this problem and it is reach to proposed objective to this study.

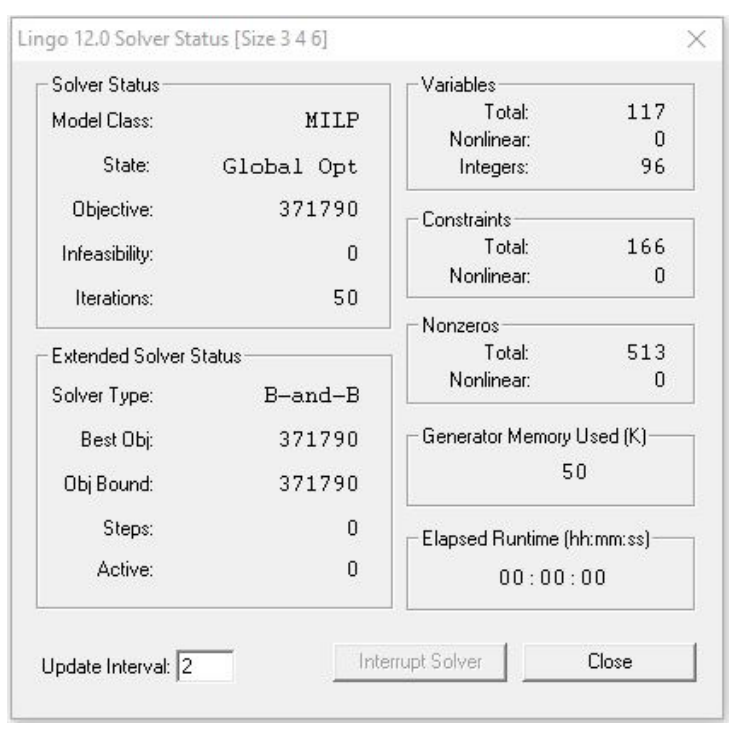

Fig. 3. Lingo output of problem size $3 \times 3 \times 6$

Table 3: Problem size and output of lingo

\begin{tabular}{|c|c|}
\hline Problem size & Total inventory cost \\
\hline $3 \times 4 \times 6$ & 371790 \\
\hline $3 \times 4 \times 12$ & 760584 \\
\hline $3 \times 4 \times 24$ & 1464030 \\
\hline $6 \times 8 \times 6$ & 586880 \\
\hline $6 \times 8 \times 12$ & 1142240 \\
\hline $6 \times 8 \times 24$ & 2282020 \\
\hline $10 \times 12 \times 6$ & 992208 \\
\hline $10 \times 12 \times 12$ & 1987310 \\
\hline $10 \times 12 \times 24$ & 3983870 \\
\hline $16 \times 18 \times 6$ & 1579020 \\
\hline $16 \times 18 \times 12$ & 3162200 \\
\hline $16 \times 18 \times 24$ & 6592040 \\
\hline $20 \times 22 \times 6$ & 1878730 \\
\hline $20 \times 22 \times 12$ & 3761870 \\
\hline $20 \times 22 \times 24$ & 7790270 \\
\hline
\end{tabular}

\section{Conclusion}

This study focuses on inventory lot sizing for supplier selection of multiple products, multiple periods of supplier selection with storage space constraint which is done in periodic review. The proposed problem is formulated as mix integer linear program (MILP) which is optimized in Lingo 12.0 software program. The result obtains a mathematical model which is able to defines optimal number of product to order from right supplier, right period to reach the objective of minimizing overall inventory cost. 


\section{References}

1. A. Atamtürk, \& S. Küçükyavuz. An O (n2) algorithm for lot sizing with inventory bounds and fixed costs. Oper. Res. Lett. 36, 297-299 (2008)

2. A.H.I. Lee, H.Y. Kang, C.M. Lai, \& W.Y. Hong. An integrated model for lot sizing with supplier selection and quantity discounts. Appl. Math. Model. 37, 4733-4746 (2013)

3. B. Karimi, S. M.T. Fatemi Ghomi , \& J.M. Wilson. The capacitated lot sizing problem: A review of models and algorithms. Omega. 31, 365-378 (2003)

4. C. Basnet, \& J. M. Y. Leung. Inventory lot-sizing with supplier selection. Comput. Oper. Res. 32, 1-14 (2005)

5. C. Woarawichai, T. Kullpattaranirun, \& V. Rungreunganun. Inventory Lot-Sizing Problem with Supplier Selection under Storage Space and Budget Constraints. Int. J. Comput. Sci. 8, 250-256 (2011)

6. D. Choudhary, \& R. Shankar. A goal programming model for joint decision making of inventory lot-size, supplier selection and carrier selection. Comput. Ind. Eng. 71, 1-9 (2014)

7. E. Senyigit, \& I. Soylemez. The Analysis of Heuristics for Lot Sizing with Supplier Selection Problem. Procedia-Soc. Behav. Sci. 62, 672-676 (2012)

8. F. Çebi, \& I. Otay. A two-stage fuzzy approach for supplier evaluation and order allocation problem with quantity discounts and lead time. Inf. Sci. 339, 143-157 (2016)

9. H. C. Bahl, L. P. Ritzman, and J. N. D. Gupta. OR Practice Determining Lot Sizes and Resource Requirements: A Review. Oper. Res. 35, 329-345 (1987)

10. H.K. Alfares \& R. Turnadi. Lot sizing and supplier selection with multiple items, multiple periods, quantity discounts, and backordering. Comput. Ind. Eng. 116, 59-71 (2018)
11. H. Ullah and S. Parveen. A Literature Review on Inventory Lot Sizing. Glob. J. Res. Eng. 10, 21-36 (2010)

12. J. Rezaei, \& M. Davoodi. Multi-objective models for lot-sizing with supplier selection. Int. J. Prod. Econ. 130, 77-86 (2011)

13. L.E. Cárdenas-Barrón, J.L. González-Velarde, \& G. Treviño-Garza. A new approach to solve the multiproduct multi-period inventory lot sizing with supplier selection problem. Comput. Oper. Res. 64, 225-232 (2015).

14. L. Guimarães, D. Klabjan, \& B. Almada-Lobo . Modeling lotsizing and scheduling problems with sequence dependent setups. Eur. J. Oper. Res. 239, 644-662 (2014)

15. LINDO Systems Inc. Lingo the modeling language and Optimizer. Chigago (2017)

16. M.M. Mazdeh, M. Emadikhiav, \& I. Parsa. A heuristic to solve the dynamic lot sizing problem with supplier selection and quantity discounts. Comput. Ind. Eng. 85, 33-43 (2015)

17. O. Ustun, \& E.A. Demirtas. An integrated multiobjective decision-making process for multi-period lot-sizing with supplier selection. Omega. 36, 509521 (2008a)

18. R. Uthayakumar, \& S. Priyan. Pharmaceutical supply chain and inventory management strategies: Optimization for a pharmaceutical company and a hospital, Oper. Res. Heal. Care. 2, 52-64 (2013)

19. S.H. Ghodsypour, \& C. O'Brien. The total cost of logistics in supplier selection, under conditions of multiple sourcing, multiple criteria and capacity constraint, Int. J. Prod. Econ. 73, 15-27 (2001) 